\title{
Can preterm birth be gainfully prevented?
}

\section{Ripan Bala*, Manmeet Kaur, Madhu Nagpal}

\begin{abstract}
Department of Obstetrics and Gynaecology, Sri Guru Ram Das Institute of Medical Sciences and Research, Vallah,
\end{abstract} Amritsar-143001, Punjab, India

Received: 30 November 2016

Accepted: 05 December 2016

\section{*Correspondence:}

Dr. Ripan Bala,

E-mail: ripanchanana@yahoo.co.in

Copyright: (C) the author(s), publisher and licensee Medip Academy. This is an open-access article distributed under the terms of the Creative Commons Attribution Non-Commercial License, which permits unrestricted non-commercial use, distribution, and reproduction in any medium, provided the original work is properly cited.

\section{ABSTRACT}

Background: Preterm birth is a major cause of perinatal deaths and a significant cause of long-term loss of human potential amongst survivors all around the world. Complications of preterm birth are the single largest direct cause of neonatal deaths, responsible for 35\% of the world's 3.1 million deaths a year, and the second most common cause of under-5 deaths after pneumonia. In almost all high and middle income countries of the world, preterm birth is a leading cause of child death. The effect of preterm birth amongst some survivors may continue throughout life, impairing neuro-developmental functioning through increasing the risk of cerebral palsy, learning impairment and visual disorders and affecting long term physical health with a higher risk of non-communicable diseases. Premature infants have to deal with variety of problems including almost every system of body. Hence the preterm birth is one of the largest single conditions in the global burden of disease analysis given in the high mortality and the considerable risk of lifelong impairment.

Methods: The present study was conducted on 100 patients admitted with spontaneous preterm labour with effect from November 2012 to March 2014. The risk factors leading to preterm labour were evaluated along with mode of delivery and neonatal outcome. The purpose of the study was to evaluate the need and success of various monitoring procedures and interventional strategies if they could improve the gestational age and gestational weight to improve perinatal outcome. The neonatologist joined in this study in providing neonatal care to reduce morbidities in these high risk preterm babies.

Results: The data was evaluated and significant prolongation of pregnancy in preterm cases was achieved by optimization of preterm births by appropriate management.

Conclusions: Identification of various risk factors leading to preterm labour and their proper management at tertiary care centre can improve the neonatal survival.

Keywords: Genitourinary infections, Prematurity, Risk factors, Prolongation of pregnancy

\section{INTRODUCTION}

Preterm birth is a syndrome with a variety of causes which can be classified into two broad subtypes. First spontaneous preterm birth (spontaneous onset of labor or following prelabour premature rupture of membranes and Second provider-initiated preterm birth (defined as induction of labour or elective caesarian birth before 37 completed weeks of gestation for both maternal (high risk pregnancies) and fetal indications.
Spontaneous preterm birth is multifactorial process, resulting from the interplay of factors causing the uterus to change from quiescence to active contractions and to birth before 37 completed weeks of gestation. The precursors to spontaneous preterm birth vary with gestational age, social, demographic and environmental factors, but in almost half of the cases cause of spontaneous preterm labour remains unidentified. ${ }^{1}$ Increasing maternal age is known to be associated with increased rates of cardiovascular disease, obesity, uterine leiomyoma, multiparity, there is an increased risk of 
hypertensive disorders of pregnancy, gestational diabetes, caesarean delivery and maternal mortality. There is also an increased risk of chromosomal abnormalities in the foetus.

Another important risk factor is uterine over distension with multiple pregnancy. The multiple pregnancies (twins, triplets, etc.) carry nearly 10 times the risk of preterm birth compared to singleton births ${ }^{1}$.Prenatal diagnosis of twin gestation in early gestation by ultrasonography can alert the obstetrician regarding need for more vigilance during antenatal period. It can also help in counselling the patient regarding possibility of adverse perinatal outcome.

There is an overwhelming evidence to implicate infection as a major cause, accounting for about $40 \%$ of spontaneous preterm labour and preterm birth. ${ }^{2}$ Urinary tract infection, bacterial vaginosis, HIV and syphilis are all associated with increased risk of preterm birth. ${ }^{3}$ In addition, other conditions have more recently been shown to be associated with infection, e.g., cervical insufficiency resulting from ascending intrauterine infection and inflammation with secondary premature cervical shortening and can lead to preterm premature rupture of membranes. ${ }^{4}$ Pregnancies with oligohydramnios are at an increased risk of adverse perinatal outcome such as foetal distress in labor, induction of labor, cesarean delivery for foetal distress, meconium passage, neonatal resuscitation or neonatal intensive care unit admission, increased risk of intrauterine growth restriction, congenital abnormalities, preterm pregnancy, abnormal foetal heart rate patterns, and lower Apgar scores. Some lifestyle factors that contribute to spontaneous preterm birth include stress and excessive physical work or long times spent standing. ${ }^{5}$

Smoking and excessive alcohol consumption as well as periodontal disease also have been associated with increased risk of preterm birth. ${ }^{3}$ Certain medical conditions (e.g. renal disease, anemia, hypertension, obesity and diabetes) increase the risk of maternal complications (e.g. pre-eclampsia) and medically indicated preterm birth. The worldwide epidemic of obesity and diabetes is, thus, likely to become an increasingly important contributor to global preterm birth. Both maternal and foetal factors are more frequently seen in pregnancies occurring after fertility treatments, thus increasing the risk of both spontaneous and provider initiated preterm births. ${ }^{6}$

Correct assessment of gestational age is very important factor in relation to preterm birth. Clinical gestational assessment based on the date of last menstrual period is practiced commonly but has low accuracy due to considerable variation in length of menstrual cycle among women, conception occurring up to several days after ovulation and the poor recall of the date of LMP being subject to errors. ${ }^{7}$
Optimizing preterm births in advance health care setting will include the various risk factors leading to preterm birth, screening them in antenatal period and managing appropriately to optimize the time of preterm birth and try to advance the pregnancy towards term with the help of medical and surgical therapies so that outcome of pregnancy improves in relation to both mother and fetus.

\section{METHODS}

100 cases with preterm birth of more than 28 wks gestation were studied at Sri Guru Ram Das Institute of medical sciences and research, Vallah (Amritsar). Direct cases who reported in OPD and referral cases were studied. Patients with singleton pregnancy, those reporting with any high risk factor deserving admission and optimization, those with any obstetrical complication before 37 weeks (requiring any intervention for maternal and foetal benefits) and those with impending preterm labour were included. Patients with multiple gestations, intra uterine foetal death and those requiring instant intervention for maternal benefit were kept out of this study. At the time of admission a detailed history of the patient including her obstetric history, menstrual history, family history and personal history was taken and gestational age was recorded. A thorough menstrual history was taken to rule out wrong dates. General physical examination was done and detailed serial obstetrical examination findings including fundal height, symphisio fundal height, abdominal girth, presentation and estimated amount of liquor was recorded. The estimated foetal weight was calculated with Johnson's formula. Periodical foetal growth assessment was observed. These parameters were duly considered for period of gestation with respect to high risk pregnancy factor. Per speculum examination was done to look for cervical conditions, discharge and collecting sample for high vaginal /cervical swab. Per vaginum examination for assessing cervical condition and Bishop's score was recorded at the time of admission and thereafter if needed. laboratory parameters studied at the time of admission were: CBC, Urine complete examination and culture sensitivity, Thyroid profile, OGTT, Viral markers, CRP, High vaginal swab, smear and culture, specific case related investigations like RFT, LFT, fundus examination which were serially repeated whenever needed were done. Ultrasonography for foetal wellbeing was done for assessing mean gestational age, amniotic fluid index, estimated fetal weight, placental localization. Transvaginal sonography was done to know cervical length and dilatation. Colour Doppler was done in suitable subjects to study vascular sufficiency of uterofetoplacental unit.

Females up to 34 weeks of gestation at the time of admission were given first dose of Betamethasone $12 \mathrm{mg}$ intramuscularly after ruling out contraindications and second dose was repeated after 24 hours.

Tocolytics were given after ruling out the contraindications such as women in active labour $>3 \mathrm{~cm}$ 
of dilatation), those with signs and symptoms of chorioamnionitis, ante partum haemorrhage or foetal distress, severe intrauterine growth retardation, congenital abnormality and women's medical conditions like cardiac disease and thyroid dysfunction. Monitoring of vitals and uterine contractions was done to adjust the dose of tocolytics. Progesterone's were given in selected cases. Amino acids and Arginine support was given in cases with foetal growth restriction and oligohydraminos. HCG as a support to precious pregnancy was used selectively. Lycopene, Calcium, iron was given in routine to all. Inj Vit k $10 \mathrm{mg}$ i/m was given to mother in some.

Antibiotics were given to those with ruptured membranes or evidence of infection found in $\mathrm{CBC}$, urine complete and culture, vaginal swab smear and culture. Non stress test was done depending upon the need of the subject. Biophysical profile was done to evaluate response to management therapy. Color Doppler findings were utilized for decision making for terminating pregnancy.

All preterm births after registration were scrutinized for prolongation of pregnancy under close foetal, maternal monitoring and decision to time of delivery. The choice of route of delivery was discussed with the subject. A written informed consent was taken from the patient/husband/relatives after detailed counselling. The maternal and foetal risks were counselled as per high risk factors. The provision of neonatologist and intensive neonatal care facilities was ensured. All high risk cases were supervised with senior faculty in the department of obstetrics and paediatrics. The detailed recordings were under close scrutiny and audit periodically. Neonatal record for $1^{\text {st }}$ week of life was included for immediate review. Tracking of subjects for late sequele could not be done because of subjects getting lost to follow up. Unpaired t test was applied to compare the results.

\section{RESULTS}

Table 1: Distribution of subjects according to risk factors in the past.

\begin{tabular}{|ll|l|}
\hline Past history & & \\
\hline Abortions & 20 & 20.00 \\
\hline Previous preterm deliveries & 11 & 11.00 \\
\hline Cervical incompetence & 3 & 3.00 \\
\hline Infertility & 6 & 6.00 \\
\hline Fibroid uterus & 2 & 2.00 \\
\hline
\end{tabular}

In the present study, $50 \%$ subjects were primigravida and $50 \%$ were multigravida. Distribution of subjects according to risk factors in the past are mentioned in Table 1 i.e. $20 \%$ had spontaneous abortions, $11 \%$ had h/o previous preterm deliveries, infertility was present in $6 \%$, cervical incompetence was found in $3 \%$ and fibroid uterus was detected in $2 \%$.
Table 2: Distribution of subjects according to risk factors in present pregnancy.

\begin{tabular}{|lll|}
\hline Complications & No. & $\%$ age \\
\hline Threatened abortion & 5 & 5.00 \\
\hline Genitourinary infection & & \\
\hline Vaginal infection & 26 & 26.00 \\
\hline UTI & 21 & 21.00 \\
\hline Chorioamnionitis & 6 & 6.00 \\
\hline PPROM & 29 & 29.00 \\
\hline APH & 11 & 11.00 \\
\hline Abruption & 9 & 9.00 \\
\hline Placenta praevia & 2 & 2.00 \\
\hline PIH & 8 & 8.00 \\
\hline Isolated oligohydraminos & 4 & 4.00 \\
\hline Polyhydramnios & 4 & 4.00 \\
\hline Malpresentation & 7 & 7.00 \\
\hline Uterine malformations & 2 & 2.00 \\
\hline
\end{tabular}

Table 3: Distribution of subjects according to urine culture.

\begin{tabular}{|lll|}
\hline Urine c/s & No. & Percentage \\
\hline Asymptomatic bacter & 8 & 8.0 \\
\hline Atypical E. coli & 1 & 1.0 \\
\hline E. coli & 6 & 6.0 \\
\hline Enterococcus & 4 & 4.0 \\
\hline S. aureus & 2 & 2.0 \\
\hline
\end{tabular}

In the present study 5 subjects had threatened abortion in first trimester in index pregnancy. Most common cause for preterm labour in study group was genitourinary infections. Vaginal infection was seen in $26 \%$ subjects, as UTI in $20 \%$ subjects and chorioamnionitis in $6 \%$ subjects. Second most common cause was preterm premature rupture of membranes (29\%). 4\% had polyhydramnios, $11 \%$ had ante partum haemorrhage. Out of which 9 had abruptio placentae and 2 had placental praevia, $8 \%$ had pre eclampsia, $7 \%$ had malpresentations. $4 \%$ had isolated oligohydraminos (Table 2).

Table 4: Distribution of subjects according to vaginal culture.

\begin{tabular}{|lll|}
\hline Vag c/s & No. & Percentage \\
\hline Candida & 3 & 3.0 \\
\hline E.coli & 7 & 7.0 \\
\hline Enterococcus & 2 & 2.0 \\
\hline H.strept & 1 & 1.0 \\
\hline Klebsiella & 4 & 4.0 \\
\hline M.morgag & 1 & 1.0 \\
\hline MRSA & 2 & 2.0 \\
\hline Proteus & 1 & 1.0 \\
\hline Pseudom & 1 & 1.0 \\
\hline S.aureus & 7 & 7.0 \\
\hline
\end{tabular}


Table 5: Relationship between Bishop Score, tocolysis and prolongation of pregnancy.

\begin{tabular}{|llll|}
\hline $\begin{array}{l}\text { Bishop } \\
\text { score }\end{array}$ & Tocolytic & $\begin{array}{l}\text { Prolongation } \\
\text { (Days) }\end{array}$ & \\
\hline $\mathbf{0 - 5}$ & 21 & Mean & SD \\
\hline $\mathbf{6 - 1 0}$ & 27 & 4.900 & 4.020 \\
\hline$>\mathbf{1 0}$ & 0 & 3.340 & 2.200 \\
\hline $\mathbf{p}$ value & & - & \\
\hline
\end{tabular}

Table 6: Distribution of subjects according to gestational age on admission $(n=100)$.

\begin{tabular}{|lll|}
\hline Gestation & No. & Percentage \\
\hline$<28$ & 9 & 9.0 \\
\hline $28-31+6$ & 29 & 29.0 \\
\hline $32-33+6$ & 28 & 28.0 \\
\hline $34-34+6$ & 34 & 34.0 \\
\hline Total & 100 & 100 \\
\hline
\end{tabular}

Table 7: Optimisation of high risk patients.

\begin{tabular}{|c|c|c|c|c|c|c|c|}
\hline \multirow[b]{2}{*}{$\begin{array}{l}\text { OBS risk } \\
\text { factor }\end{array}$} & \multirow[b]{2}{*}{$\begin{array}{l}\text { No of } \\
\text { patients }\end{array}$} & \multicolumn{5}{|c|}{ Medical therapy } & \multirow[b]{2}{*}{$\begin{array}{l}\text { Mean } \\
\text { prolongation } \\
\text { of days }\end{array}$} \\
\hline & & $\begin{array}{l}\text { Mean } \\
\text { Gest. } \\
\text { Age wks) }\end{array}$ & Antibiotics & Tocolysis & Betamethasone & Alanine & \\
\hline Threatened abortion & 5 & $32+6$ & 0 & 5 & 5 & 1 & 3 \\
\hline \multicolumn{8}{|l|}{$\begin{array}{l}\text { Genitourinary } \\
\text { infection }\end{array}$} \\
\hline Vaginal infection & 26 & $32+4$ & 24 & 13 & 16 & 4 & 3.71 \\
\hline UTI & 21 & $31+3$ & 18 & 10 & 16 & 1 & 5.1 \\
\hline Chorioamnionitis & 6 & 30 & 6 & 4 & 5 & 0 & 3 \\
\hline PPROM & 29 & $32+1$ & 27 & 15 & 20 & 0 & 3.58 \\
\hline $\mathrm{APH}$ & 11 & & & & & & \\
\hline Abruption & 9 & 32 & 0 & 0 & 7 & 0 & 0 \\
\hline Placenta previa & 2 & 36 & 1 & 0 & 0 & 0 & 0 \\
\hline $\mathrm{PIH}$ & 8 & $31+2$ & 2 & 3 & 5 & 1 & 6.6 \\
\hline Oligohydraminos & 5 & $32+5$ & 4 & 2 & 1 & 4 & 3.5 \\
\hline Polyhydramnios & 4 & $31+2$ & 0 & 1 & 2 & 0 & 1 \\
\hline Malpresentation & 7 & $31+2$ & 1 & 4 & 6 & 0 & 5.75 \\
\hline $\begin{array}{l}\text { Uterine } \\
\text { malformations }\end{array}$ & 2 & $33+5$ & 0 & 1 & 1 & 0 & 2 \\
\hline
\end{tabular}

Twenty seven per cent subjects in our study had associated medical co-morbid conditions during this pregnancy. In our study, $2 \%$ subjects had gestational diabetes and $1 \%$ had diabetes mellitus Type 1 . In our study $4 \%$ patients had thyroid disorders, out of which 3 had hypothyroidism and 1 had hyperthyroidism. Other medical conditions found in our subjects with preterm labour were: Jaundice in $7 \%$ subjects. Three of them were diagnosed as hepatitis $\mathrm{E}$ reactive and 1 was hepatitis $\mathrm{C}$ positive. One patient in our study had cholestasis of pregnancy.

$10 \%$ females had acute febrile illness at admission, $2 \%$ had upper respiratory tract infections and bronchitis, 1 had acute pyelonephritis. 5\% subjects had gastroenteritis, $3 \%$ subjects had tuberculosis.

One subject had thrombotic stroke in pregnancy following which she had preterm labour pains. Two patients in our study had undergone surgeries during pregnancy prior to onset of preterm labour pains. One had laparotomy for acute intestinal obstruction and one had stenting.
Mean Bishop core was 7.51 with a standard deviation of 2.52. Patients with Bishop's score 0-5, 6-10 and more than 10 comprised $27 \%, 60 \%$ and $13 \%$ respectively. Out of 100 patients, $48 \%$ received tocolysis. $77.78 \%$ received tocolysis with Bishop Score 0-5 and $45 \%$ received with Bishop Score 6-10. None of the patients with a Bishop's score of $>10$ was given tocolysis and this difference was statistically significant ( $\mathrm{p}$ value $=0.00$ ).

$40 \%$ subjects were anaemic, $26 \%$ subjects had TLC $\geq$ $15000 /$ cumm and $33 \%$ subjects had CRP >/= $5 \mathrm{mg} / \mathrm{L}$. Urine culture was positive in $21 \%$ patients. Most common organism isolated was E.coli (6\%), Enterococcus (4\%), Staphylococcus aureus 2\%, atypical E.coli $1 \%$ and $8 \%$ patients had asymptomatic bacteriuria (Table 3).

$29 \%$ subjects had positive vaginal cultures. Most common organisms isolated were Staphylococcus aureus and E.coli (7\% each). Other organisms were Klebsiella 4\%, Candida 3\%, MRSA 2\%, Proteus mirabilis $1 \%$ and Enterococcus 2\%. Non hemolytic streptococci, 
Pseudomonas, Morganella morgagni, Hemolytic streptococcus were isolated in $1 \%$ (Table 4).

Mean prolongation of pregnancy for subjects with a Bishops score of $<5$ was 4.90 days and for subjects with a Bishops score of 6-10 was 3.34 days. None of the patients with a Bishop's score of $>10$ got tocolysis and delivered on the same day of admission (Table 5).

At the time of admission 9\% subjects were below 28 weeks gestation, $29 \%$ were 28 to $31+6$ weeks gestation, $28 \%$ were 32 to $33+6$ weeks of gestation and majority $(34 \%)$ were between $34-36+6$ weeks of gestation (Table 6)

Out of 100 preterm deliveries 65 were vaginal deliveries and 34 were LSCS and 1 was instrumental delivery. At less than 28 weeks of gestation $77.78 \%$ had vaginal deliveryand $22.22 \%$ had caesarean section. At 28 to 32 weeks $68.97 \%$ delivered vaginally and $31.03 \%$ had caesarean. At 32 to 34 weeks $71.43 \%$ had vaginal delivery and $28.57 \%$ had caesarean. At $34-36+6$ weeks $55.58 \%$ had vaginal and $44.12 \%$ had caesarean.

Foetal distress in 13 patients, malpresentations with 6 Breech and one with Transverse lie. 8 patients with hypertensive disorder of pregnancy underwent caesarean with 3 having associated severe IUGR and severe oligohydramnios, other 3 patients had abruption with non-progress of labour and 2 had eclampsia. 2 were of major degree placenta praevia, 3 patients had previous LSCS and 1 patient had stroke during the antenatal period and underwent $\mathrm{L}$

Premature babies suffered a lot of morbidities. 23\% of neonates in our study developed respiratory distress syndrome, $1 \%$ had transient tachypnoea of new-born and $1 \%$ had congenital pneumonia. Neonatal hyperbilirubinemia was seen in $27 \%$ new-borns. $3 \%$ neonates developed coagulopathy, 3\% hypocalcaemia and $2 \%$ hypoglycaemia, sepsis $10 \%$, necrotizing enter colitis $7 \%$ were other common neonatal complications.

Congenital malformations were present in $2 \%$ babies. Out of these two babies, 1 had congenital heart disease, 1had tracheo-esophageal fistula.

At gestation <28 weeks $66.67 \%$ babies developed RDS. Between 28-31+6 weeks $37.93 \%$ babies developed RDS. At 32 to $33+6$ weeks $3.57 \%$ babies developed RDS. At 34-36+6 weeks gestation none developed RDS which is statistically significant.

$77.78 \%$ babies weighing $<0.99 \mathrm{~kg}$ developed RDS. $47.62 \%$ babies weighing 1-1.499 had RDS. 5.26\% babies weighing 1.5-2.499 kg developed RDS. This difference was significant.

66 babies had received antenatal steroids. 41 received (two) standard doses and 25 had only (one) non-standard dose of antenatal steroids and 34 did not receive steroids.19.70\% babies receiving antenatal steroids developed RDS. Only $53.30 \%$ babies receiving single dose of steroids developed RDS while $33.30 \%$ babies who received two doses of steroids developed RDS. This dose relationship finding is statistically significant.

Below 28 weeks mortality rate was $33.33 \%$, between 28 to $31+6$ weeks mortality rate was $27.59 \%$, at 32 to $33+6$ weeks mortality rate was $3.57 \%$. At $34-36+6$ weeks mortality rate was $2.94 \%$. In 4 subjects pregnancy was prolonged beyond 37 weeks with tocolytics and in this group survival rate was $100 \%$.

$16.66 \%$ babies delivered by vaginal delivery expired while $5.8 \%$ babies delivered by LSCS expired.

Extremely low birth weight infants had a mortality rate of $44.44 \%$. Between 1 to $1.499 \mathrm{kgs}$ mortality rate was $33.33 \%$. Between 1.5 to $2.4999 \mathrm{kgs}$ mortality rate was $1.75 \%$.Mortality rate was $7.69 \%$ in babies weighing $\geq 2.5$ $\mathrm{kg}$.

Out of 100 babies born and studied, 79\% were discharged in a healthy condition, $13 \%$ expired whereas $8 \%$ left against medical advice due to financial constraints. The purpose of optimisation is to gain gestational age and weight in order to improve perinatal outcome.

The summary findings in this table demonstrate that there is mean prolongation of days by an average 3.10 days. Often patients had one or more compounding risk factors and other co morbidities which affected mean gain in gestational age. The mean gain was in use of antenatal steroids (Table 7).

\section{DISCUSSION}

In our study $50 \%$ patients were primigravida and $50 \%$ were multigravida. Similarly Singh Uma et al had $47 \%$ primigravidas and $53 \%$ multigravidas in their study. ${ }^{8}$ Etiology of preterm labour are multifactorial. Past reproductive outcome has a great impact on the next pregnancy.

In our study $20 \%$ subjects had a past history of abortions which is more or less consistent with the incidence reported by Uma $\mathrm{S}$ et al, Trivedi DR et al and Chhabra $\mathrm{S}$ et al and. ${ }^{8-10}$ Above discussion shows that history of previous abortions poses a risk for preterm labour in future pregnancies.

$11 \%$ patients in our study had spontaneous preterm deliveries in the past which is similar to findings of Uma $\mathrm{S}$ et al, Trivedi DR et al, Chhabra $\mathrm{S}$ et al, Pandey K et al, Lykee JA, Al Dabbagh SA, Jean Marie Moutquin et al and Hay PE. ${ }^{8-15}$

In our study $3 \%$ subjects had history of cervical incompetence, in the past. According to Arias F, 
approximately $5 \%$ of the preterm births occur because of anatomical or physiological abnormalities of cervix. Incompetent cervix secondary to cervical conditions contributes to $3 \%$ cases of preterm labour. ${ }^{16}$ Nohr B et al concluded that there is almost 2 fold increased risk of preterm labour after loop electrosurgical excision of the cervix. $^{17}$

In our study $6 \%$ patients had history of infertility in the past. Similarly Thyagarajan $\mathrm{C}$ et al concluded that there is increased incidence of preterm labour in females with history of infertility. ${ }^{18}$

In our study $5 \%$ subjects had history of threatened abortion in the present pregnancy. alike the study reported by Weiss JL et al i.e. threatened abortion is a risk factor for poor pregnancy outcome including preterm labour. $^{19}$

$21 \%$ females had urinary tract infection, $13 \%$ females had positive urine culture on admission and $8 \%$ females had asymptomatic bacteriuria. Mean gestational age was $31+3$ weeks. 18 subjects received antibiotics, 10 received tocolysis, 16 received betamethasone and 1 received alamine infusion. Mean prolongation of 5.1 days was seen which is consistent with the findings of Uma $\mathrm{S}$ et al, Chhabra $\mathrm{S}$ et al Pandey $\mathrm{K}$ et al, Al Dabbagh SA, Kilpatrick SJ and Romero R et al. , $^{8,10,11,13,20,21}$

$26 \%$ females in our study had positive vaginal cultures. Mean gestational age at admission was $32+4$ weeks. 24 received antibiotics, 13 received tocolysis, 16 received betamethasone and 4 received alamine infusions. Mean prolongation of days in these subjects was 3.71. Similarly Chhabra $\mathrm{S}$ et al found that genital tract colonization was a common risk factor for preterm labour seen in $28 \%, 25 \%$ and $40 \%$ of their subjects respectively. ${ }^{10}$

$6 \%$ subjects in our study had chorioamnionitis. There mean gestational age at admission was 30 weeks.6 subjects received antibiotics, 4 tocolysis and 5 betamethasone. Mean prolongation of 3 days was seen in them. Similarly Uma $\mathrm{S}$ et al reported chorioamnionitis in $4.2 \%$ of their subjects and Pandey $\mathrm{K}$ reported it in $3 \%$ of their subjects. ${ }^{8,11}$ According to Fernando Arias $\mathrm{F}$ chorioamnionitis is associated with $10 \%$ of the cases with preterm labour. $^{16}$

In our study common cause of preterm labour was preterm premature rupture of membranes which was associated with $29 \%$ preterm births. This is in accordance with the study of Uma Set al and Arias F and et al. ${ }^{8,16}$

In our study $11 \%$ subjects had antepartum haemorrhage. Out of these 9 had abruptio placentae. There mean gestational age at admission was 32 weeks. None of the subjects received antibiotics, none tocolysis and 7 betamethasone. Mean prolongation of 0 days was seen in them. 2 had placenta praevia. There mean gestational age at admission was 36 weeks. None of the subjects received antibiotics, none tocolysis and none betamethasone. Mean prolongation of 0 days was seen in them. This is in accordance with Uma $\mathrm{S}$ et al's result that $10.8 \%$ patients with preterm labour had antepartum haemorrhage.

In our study 7 patients had pre-eclampsia, 1 had eclampsia. In Uma S et al's study $3.7 \%$ subjects had severe pre eclampsia. There mean gestational age at admission was $31+2$ weeks. 2 subjects received antibiotics, 3 tocolysis, 5 betamethasone and 1 received alamine infusion. Mean prolongation of 6.6 days was seen in them. ${ }^{8}$

In our study $4 \%$ subjects had polyhydramnios. There mean gestational age at admission was $31+2$ weeks. None of the subjects received antibiotics, 1 tocolysis and 2 betamethasone. Mean prolongation of 1 day was seen in them

Uma $\mathrm{S}$ et al reported $3.4 \%$ patients with polyhydramnios, Pandey $\mathrm{K}$ et al reported that polyhydramnios was present in 2.06 percent of their subjects with preterm labour. ${ }^{8,11}$

In our study $7 \%$ subjects had malpresentations. $6 \%$ were breech and $1 \%$ transverse lie. There mean gestational age at admission was $31+2$ weeks. 1 of the subjects received antibiotics, 4 tocolysis and 6 betamethasone. Mean prolongation of 5.75 days was seen in them. In Uma S et al's study $14.4 \%$ subjects had malpresentations. ${ }^{8}$

$2 \%$ patients in our study had uterine malformations, both of the patients had bicornuate uterus. $2 \%$ had fibroid uterus. There mean gestational age at admission was $33+5$ weeks. None of the subjects received antibiotics, 1 tocolysis and 1 betamethasone. Mean prolongation of 2 days was seen in them which is in accordance with Uma $\mathrm{S}$ et al's observation and of Pandey $\mathrm{K}$ et al. ${ }^{8,11}$

$28 \%$ subjects in our study had associated medical comorbid conditions during this pregnancy which is consistent with Uma $\mathrm{S}$ et al's study group where $22.1 \%$ subjects had medical disorders and in Pandey $\mathrm{K}$ et al's group $19.65 \%$ subjects had maternal medical disorders. ${ }^{8,11}$

In our study, $2 \%$ subjects had gestational diabetes and $1 \%$ subjects had diabetes mellitus type 1 . Preterm delivery was associated with significant neonatal morbidity as the risks for neonatal hypoglycaemia and respiratory distress syndrome were increased by three to six fold compared with the reference group ${ }^{.22}$ Hence it can be concluded that diabetes is a risk factor for preterm delivery.

In our study, $3 \%$ patients had thyroid disorders, out of which 2 had hypothyroidism and 1 had hyperthyroidism. Alex Stagnaro-Green conducted study on maternal thyroid disease and preterm delivery and found that hypothyroidism and autoimmune thyroid disease in euthyroid women are associated with preterm delivery and there occurs a dramatic decrease in the incidence of 
preterm delivery in thyroid antibody-positive women treated with levothyroxine. ${ }^{23}$

Mean haemoglobin level in our study was 10.52 with a standard deviation of 1.91. In the study of Pandey Kiran et al105 subjects had haemoglobin level $<6 \mathrm{~g} / \mathrm{dl}$. Mean haemoglobin level in their study was $8.65 \mathrm{~g} / \mathrm{dl}^{11}$ Anaemia was common $(40 \%)$ in our study group and is also reported by Karasahin E. ${ }^{24}$

In our study $13 \%$ had growth in urine culture.Most common organism found was E. coli $(41.66 \%)$ followed by Enterococcus (33.33\%), Staphylococcus aureus (16.66\%) and atypical E. coli (8.33\%). In Uma S et al's study $E$. coli was the commonest organism followed by Klebsiella, Staphylococcus and Citrobacter. ${ }^{8}$

In our study, 29\% females had positive vaginal cultures. Most common organisms isolated were Staph aureus and E. coli $7 / 26(26.92 \%)$ followed by Klebsiella $3 / 26$ (15.38\%). Candida was isolated from 3 subjects. MRSA, Proteus mirabilis, Enterococcus present were in 2 subjects each and non hemolytic Streptococcus, Pseudomonas, Morganella, Hemolytic streptococcus was present in 1 patient each. Singh $U$ et al $^{13}$ found positive vaginal culture in $12.25 \%$ patients with E. coli and Staph aureus having commonest organisms (32\% each) isolated followed by Candida, Klebesiella and Trichomonas and Deka D et al found that cervical infection was present in $11 / 20(55 \%)$ patients and organisms isolated were Staphylococcus aureus, Micro aerophilic gram positive non sporing bacilli and Peptostreptococcus. ${ }^{25}$

Average Bishop's score on admission in the study group was $7.51 \pm 2.52$. Majority $(60 \%)$ had a Bishop's score of $6-10,27 \%$ had a Bishop's score $\leq 5,13 \%$ subjects had a Bishop's score $>10$ at the time of admission.

In our study $48 \%$ subjects were given tocolysis. We commonly used beta agonists-isoxsuprine/ritodrine for tocolysis. Twenty out of twenty six subjects with a Bishop's score of 0-5 received tocolysis. Six patients were not given tocolysis. 5 out of these were > 34 weeks gestation and 1 had abruption.

Twenty seven out of sixty patients with a Bishop's score of 6-10 received tocolysis. Thirty three out of sixty subjects in this group were not given tocolysis. Reason for this was gestation more than 34 weeks, dilatation more than $3 \mathrm{cms}$, fetal distress, antepartum haemorrhage and chorioamnionitis.

None of the patients with a Bishop's score $>10$ received tocolysis.

Mean prolongation of pregnancy for subjects with a Bishop's score less than 5 was 4.9 days, for patients with a Bishop's score of 6-10 was 3.34 days and in subjects with a Bishop's score more than 10, pregnancy could not be prolonged.
In Pandey et al's study 55\% females had a cervical dilatation of $<2 \mathrm{~cm}$ and in majority $(96.4 \%)$ of these pregnancy was prolonged. Subjects with $3 \mathrm{~cm}$ dilatation, $47.5 \%$ delivered within $48 \mathrm{hrs}$ and with cervical dilatation of $4 \mathrm{~cm}$ all delivered within 48 hours i.e. cervical dilatation is inversely related to prolongation of pregnancy with tocolysis. ${ }^{11}$

In Nagpal P et al's study to evaluate the role of Nifedipine in suppression of preterm labour, $14.66 \%$ subjects had tocolytic effect lasting for upto 3 days. In $5.33 \%$ labour was prolonged upto 3-7 days. ${ }^{26}$

In Waheed A et al's study, $58 \%$ of the pregnant females delivered after $48 \mathrm{hrs}, 26 \%$ between 24-48 hours and $16 \%$ delivered before 24 hrs. $^{27}$

Singh S et al evaluated role of Nifedipine in preterm labour. Majority (40/65) of the subjects had cervical dilatation less than $2 \mathrm{cms}$. In them mean prolongation was 26.65 days. 25/65 subjects had cervical dilatation of $\geq 2 \mathrm{cms}$ and mean prolongation was 11.86 days. $^{28}$

Hence it can be concluded that tocolytics help in prolongation of pregnancy up to few days and the prolongation pregnancy is inversely related to Bishop's score and cervical dilatation.

$66 \%$ babies had received antenatal steroids, 41 of them received standard dose and 25 of them received nonstandard dose of betamethasone. 34 babies were not given antenatal steroids. $33.33 \%$ babies with standard antenatal steroid coverage developed RDS and $53.30 \%$ babies with non-standard antenatal steroid coverage had RDS. In Venkat $\mathrm{S}$ et al's study babies who received standard antenatal steroid coverage, only $15 \%$ of them developed RDS compared to $58 \%$ in the non-standard group. $^{29}$

This shows that complete dosage of antenatal steroids have better protection than non-standard dosages.

Steroid covered group had $19.70 \%$ incidence of RDS and Only $15.8 \%$ babies who did not receive antenatal steroids had RDS. This difference however, is not statistically significant. This is in contrast to Uma $\mathrm{S}$ et al's study where incidence of RDS was significantly high in babies without steroid coverage than in those with steroid coverage $(26.8 \%$ vs $10 \%)$. This difference is probably because larger proportion of the babies who developed RDS was less than 28 weeks which itself predisposes to RDS. $^{8}$

In our present study it was observed that neonatal mortality was highest in the lower birth weight groups and survival rate increased as the birth weight increased as also reported by Waheed A et al, Venkat $\mathrm{S}$ et al, and Jotwani MJ et al. ${ }^{27,29,30}$ It is clear from above studies that birth weight and neonatal mortality is inversely related. 
In our study, perinatal mortality rate was $13 \%$, survival rate was $79 \%$ and $8 \%$ babies left against medical advice because of poor prognosis or financial constraints. The management strategies included investigations, monitoring as well as interventions. Our primary aim was optimizing the benefits $\mathrm{v} / \mathrm{s}$ risk of each case in consideration of the adverse outcome as related to gain of gestational age/weight, as these factors were two most important parameters affecting outcome. In the last few years percentage of new-borns born at lesser gestational age is increasing. This is because of better neonatal survival and lesser morbidity because of advances in neonatology as reported by Trivedi DR which is very much like the present study. ${ }^{9}$

However, optimum gain was 3.10 days on an average as illustrated in Table no 7. The tocolytics helped in prolongation of pregnancy up to few days and the prolongation of pregnancy is inversely related to Bishop' score and cervical dilatation as also reported by various other authors i.e. Pandey K et al, Nagpal P et al, and Singh S. et al. ${ }^{11,26,28}$ Unique observation was use of injection Betnesol (two doses) improving the outcome and reducing the morbidities. Other interventions were of no significant value other than psyche improvement. So, gain of days was more beneficial in view of betnesol use. Similar observations have been reported and discussed by Ventak S et al. ${ }^{29}$ Route of delivery mostly accepted by patients in view of altered neonatal outcome was vaginal delivery which is similar to the observation and conclusion reported by Venkat $\mathrm{S}$ et al and Jotwani MJ etal and Sonkusare S. ${ }^{29-31}$

\section{Funding: No funding sources}

Conflict of interest: None declared

Ethical approval: The study was approved by the Institutional Ethics Committee

\section{REFERENCES}

1. Blondel B, Macfarlane A, Gissler M. Preterm birth and mulyiple pregnancy in European countries participating in PRESTAT project. BJOG. 2006;113(5):528-35.

2. Lettiere L, Vintzileos AM, Rodis JF. Does idiopathic preterm labor resulting in preterm birth exist? Am J Obstet Gynaecol. 1993;168:1480-5.

3. Gravett MG, Rubens CE. Global report on preterm birth and still birth (2 of 7): discovery science. BMC pregnancy child birth. 2010;10:1, 2.

4. Lee SE, Romero R. The frequency and significance of intraamniotic inflammation in patients with survical insufficiency. American journal of obstetrics an gynaecology. 2008;198(6),633e:631-8.

5. Muglia LJ, Katz M. The enigma of spontaneous preterm birth. The New England Journal of medicine. 2010;362(6):529-35.

6. Kent AL, Wright IM, Abdel-Latif ME. Mortality and adverse neurologic outcomes are greater in preterm male infants. 2008;129(1):124-31.
7. Kramer MS, McLean FH, Boyd ME. The validity of gestational sge estimation by menstrual dating in term, preterm and post term gestations. JAMA: the journal of the American Medical Association. 1998;260(22):3306-8.

8. Uma S, Nisha $\mathrm{S}$, Shikha S. A prospective analysis of etiology and outcome of preterm labor. J Obstet Gynecol India. 2007;57:48-52.

9. Trivedi DR, Nagpal SP. Preterm delivery: A common obstetric problem. J Obstet and Gynaecol India. 1995;45:380-84.

10. Chhabra S, Patil N. Study of factors causing and arresting preterm labour. J Obstet Gynecol India. 2001;51:99-103.

11. Pandey K, Bhagoliwal A, Gupta N, Geetanjaly K. Predictive value of various risk factors for preterm labor. J Obstet Gynecol India. 2010;60:141-5.

12. Lykke JA, Paidas MJ, Langhoff-Roos J. Recurring complications in second pregnancy. Obstet Gynecol. 2009;113(6):1217-24.

13. Al-Dabbagh SA, Al-Taee WY. Risk factors fore preterm birth in Iraq: a case-control study. BMC Pregnancy and Childbirth. 2006;6:13.

14. Moutquin JM. Classification and heterogeneity of preterm birth. BJOG. 2003;110:30-3.

15. Hay PE, Lamont RF, Taylor-Robinson D, Morgan D, Ison C, Pearson J. Abnormal bacterial colonization of the genital tract and subsequent preterm delivery and late miscarriage. BMJ. 1994;308:295-303.

16. Arias F, Daftary SN, Bhide A. Preterm parturition syndrome. Practical guide to high risk pregnancy and delivery. $3^{\text {rd }}$ edition, pg. 193.

17. Nohr B, Tabor A, Frederiksen K, Kjaer SK. Loop electrosurgical excision of the cervix and the subsequent risk of preterm delivery.

18. Thyagarajan C, Dasari P, Habeebullah S. Maternal and perinatal outcome in pregna following infertility. Int J Infert Fetal Med. 2010;1:24-9.

19. Weiss JL, Malone FD, Vidaver J, Ball RH, Nyberg DA, Comstock CH, Hankins GD et al. Threatened abortion: a risk factor for poor pregnancy outcome, a population-based screening study. Am J Obstet Gynecol. 2004;190:745-50.

20. Kilpatrick SJ, Patil R, Connell J, Nichols J, Studee L. Risk factors for previable premature rupture of membranes of advanced cervical dilation: A case control study. Am J Obst Gyn. 2006;194:1168-75.

21. Romero R, Oyarzun E, Mazor M, Sirtori M, Hobbins JC, Bracken M. Meta-analysis of the relationship between asymptomatic bacteriuria and preterm delivery/low birth weight. Obstet Gynecol. 1989;73(4):576-82.

22. LepercQ J, Coste J, Theau A, Dubois-Laforgue D, Timsit J. Factors associated with preterm delivery in women with type 1 diabetes. Diabetes Care. 2004;27:2824-8.

23. Stagnaro-Green A. Maternal thyroid disease and preterm delivery. J Clin Endocrinol Metab. 2009;94:21-5. 
24. Karasahin E, Ceyhan ST, Goktolga U, Keshkin U, Baser I. Maternal anemia and perinatal outcome. Perinatal J. 2007;15:127-30.

25. Deka D, Buckshee K, Kharsyntiew B, Rakshit AK. Significance of risk scoring system in the identification of pregnant women at high risk for preterm labour in India. $\mathrm{J}$ Obstet Gynaecol. 1997;47:487-92.

26. Nagpal P, Maheshwari M, Sunder K. The role of nifedipine ( $\mathrm{Ca}$ channel antagonist) in suppression of pre-term labour. J Obstet Gynaecol India. 1998;48:35-8.

27. Waheed A, Shami N. Preterm labour effectiveness of transdermal gly trinitrate patch. Professioanl Med J. 2011;18:174-80.

28. Singh S, Gupta K and Ahluwalia G. Role of nifedipine in preterm labour and it's effect on perinatal outcome. J Obstet Gynaecol India. 1993;43:687-92.

29. Venkat S, Nayyar R, Bhat J. Retrospective analysis of spontaneous v/s induced preterm deliveries and neonatal outcome. Obstet Gynecol Ind. 2003;53:468.

30. Jotwani MJ, Bhute SB, Deshmukh KK. Evaluation of perinatal morbidity and mortality in preterm labour. J Obst Gyn India. 2001;51:34-7.

31. Sonkusare S, Rai L, Naik P. Preterm birth: Mode of delivery and neonatal outcome. Med J Malaysia. 2009;64:303-06.

Cite this article as: Bala R, Kaur M, Nagpal M. Can preterm birth be gainfully prevented? Int J Reprod Contracept Obstet Gynecol 2017;6:6-14. 